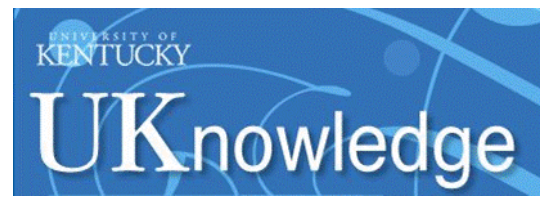

University of Kentucky

UKnowledge

\title{
Development and Preliminary Evaluation of an Integrated Individual Nozzle Direct Injection and Carrier Flow Rate Control System for Pesticide Applications
}

Joe D. Luck

University of Nebraska-Lincoln

Scott A. Shearer

The Ohio State University

Michael P. Sama

University of Kentucky, michael.sama@uky.edu

Follow this and additional works at: https://uknowledge.uky.edu/bae_facpub

Part of the Bioresource and Agricultural Engineering Commons

Right click to open a feedback form in a new tab to let us know how this document benefits you.

\section{Repository Citation}

Luck, Joe D.; Shearer, Scott A.; and Sama, Michael P., "Development and Preliminary Evaluation of an Integrated Individual Nozzle Direct Injection and Carrier Flow Rate Control System for Pesticide Applications" (2019). Biosystems and Agricultural Engineering Faculty Publications. 250. https://uknowledge.uky.edu/bae_facpub/250

This Article is brought to you for free and open access by the Biosystems and Agricultural Engineering at UKnowledge. It has been accepted for inclusion in Biosystems and Agricultural Engineering Faculty Publications by an authorized administrator of UKnowledge. For more information, please contact UKnowledge@lsv.uky.edu. 
Development and Preliminary Evaluation of an Integrated Individual Nozzle Direct Injection and Carrier Flow Rate Control System for Pesticide Applications

Digital Object Identifier (DOI)

https://doi.org/10.13031/trans.13170

Notes/Citation Information

Published in Transactions of the ASABE, v. 62, issue 2.

@ 2019 American Society of Agricultural and Biological Engineers

The copyright holder has granted the permission for posting the article here.

The document available for download is the authors' post-peer-review final draft of the article. 


\title{
DeVelopMent AND PReliminary EVAluation OF AN INTEGRATED INDIVIDUAL NOZZLE DIRECT INJECTION/CARRIER FLOW RATE CONTROL SYSTEM FOR PeSTICIDE APPLiCATIONS
}

\author{
J.D. Luck, S.A. Shearer, and M.P. Sama
}

\begin{abstract}
Direct injection systems for agricultural spray applications continue to present challenges in terms of commercialization and adoption by end-users. Such systems have typically suffered from lag time and mixing uniformity issues which have outweighed potential benefits from keeping chemical and carrier separate or reducing improper tank-mixed concentration by eliminating operator measurements. The proposed system seeks to combine high pressure direct nozzle injection with an automated variable-flow nozzle to improve chemical mixing and response times. The specific objectives were to: 1) integrate a high pressure direct nozzle injection system with variable flow carrier control, 2) assess chemical metering accuracy and proper mixing at different combinations of injection valve frequency and duty cycle along with chemical pressure, and 3) assess the ability of the control system to ensure proper chemical dilutions and concentrations in the nozzle effluent resulting from step changes for target application rates. Laboratory experiments were conducted using the combined system; Results of these experiments showed that the open-loop control of the injectors could provide a means of accurately metering the chemical concentrate into the carrier stream. Chemical injection rates could be achieved with an average error of $5.4 \%$ compared to the target rates. Injection at higher duty cycles resulted in less error in the chemical concentration predictions. Discrete Fourier transform analysis showed that the injection frequency was noticeable in the nozzle effluent when the injector was operated at $3.04 \mathrm{MPa}$ and $5 \mathrm{~Hz}$ (particularly at lower duty cycles). Increasing the injection pressure and operating frequency to $5.87 \mathrm{MPa}$ and $7 \mathrm{~Hz}$, respectively, improved mixing as the injection frequency component was no longer noticed in the effluent samples. The variable flow nozzle was able to maintain appropriate carrier flow rates to achieve product label chemical concentrations. In one case, the maximum allowable concentrate was exceeded, although the nozzle was able to recover in $0.5 \mathrm{~s}$. Steady state errors ranged from $2.5 \%$ to $7.5 \%$ for chemical concentrations compared to the selected chemical to carrier ratio (0.03614). This test scenario represented an application rate of $4.68 \mathrm{~L} / \mathrm{ha}$ with increases from 4.0 to $7.1 \mathrm{~m} / \mathrm{s}$ and decreases from 7.1 to $4.0 \mathrm{~m} / \mathrm{s}$ which were typical of the field application data example.
\end{abstract}

Keywords. Spraying equipment; precision agriculture; pesticides; variable rate application

The information reported in this paper (No. $\mathrm{xx}-\mathrm{xx}-\mathrm{xx}$ ) is part of a project of the Kentucky Agricultural Experiment Station and is published with the approval of the Director. Mention of trade names is for informational purposes only and does not necessarily imply endorsement by the Kentucky Agricultural Experiment Station.

The authors are Joe D. Luck, ASABE Member, Associate Professor, Department of Biological Systems Engineering, University of Nebraska-Lincoln, Lincoln, Nebraska; Scott A. Shearer, ASABE Member, Professor and Chair, Department of Food, Agricultural and Biological Engineering, The Ohio State University, Columbus, Ohio; and Michael P. Sama, ASABE Member, Assistant Professor, Department of Biosystems and Agricultural Engineering, University of Kentucky, Lexington, Kentucky. Corresponding author: Joe D. Luck, Department of Biological Systems Engineering, 204 L.W. Chase Hall, University of Nebraska-Lincoln, Lincoln, NE 68583-0726; phone: 402-472-1488; fax: 402-472-6338; e-mail: jluck2@unl.edu. 


\section{INTRODUCTION}

Direct injection systems have long been proposed as a potential alternative to tank-mixing chemicals prior to field application. While a significant amount of research has been published regarding such systems, few commercially available systems are available on the market. For most commercially available systems, the chemical concentrate is pressurized separately from the carrier and injected ahead of one or more subsections of the spray boom.

Two primary issues related to direct injection systems are related to high lag times during transient conditions as well as poor mixing of the injected chemical prior to nozzle discharge. Under simulated conditions, Way et al. (1992) predicted increased field application errors using direct injection sprayers compared to conventional tank mix sprayers. Sudduth et al. (1995) evaluated a commercially available systems (Raven SCS-700) and reported delay times up to 21 $\mathrm{s}$ in response to ground speed changes. Further studies were conducted on the same system after the addition of carrier flow control; however, errors were still present with the updated system (Steward and Humburg, 2000). Other direct injection systems have been evaluated, which demonstrated lag times between 15 and $55 \mathrm{~s}$ based on the carrier flow rate (Anglund and Ayers 2003). In an effort to improve direct injection systems, several simulation studies have been conducted which have found that reducing boom line diameters (Zhu et al. 1998a \& 1998b) or combining this modification with decreasing the distance between chemical injection point and nozzle Qui et al. (1998) could provide reduced lag times. While lag times were shown to be reduced, the secondary problem of proper mixing could still prove to be an issue. Thus, much of the more recent research has focused on direct nozzle injection systems, where the injection point is located as close in proximity to the nozzle as possible.

A prototype direct nozzle injection system tested by Miller and Smith (1992) injected chemical via a metering orifice immediately upstream of the nozzle. Chemical pressure was increased from $70 \mathrm{kPa}$ to $483 \mathrm{kPa}$, which resulted in nozzle-to-nozzle CVs from $3.4 \%$ to $2.2 \%$, respectively. This showed the potential for improved uniformity across the spray boom, but did not evaluate the mixing variation from any individual nozzle. A common theme for improving mixing has been to increase chemical injection pressure settings, typically less than $700 \mathrm{kPa}$. More recently, Luck (2010) developed a system which used extremely high (8.27 MPa) chemical pressures to improve mixing of the chemical and carrier. A direct-acting solenoid valve pulsed at frequencies between 5 and $8 \mathrm{~Hz}$ (duty cycle from 10\% to $90 \%$ ) produced the best results with a system time constant of $0.3 \mathrm{~s}$. Chemical concentrate mixing was also found to be acceptable across the nozzle pattern and along the direction of travel which was believed to be a result of injecting the chemical at such a high pressure. Another potential problem with direct injection systems lies in the fact that 
chemical-to-carrier dilutions must be maintained within minimum and maximum limits as per a pesticide product label. For instance, a certain rate range of chemical might be applied within a specified carrier application rate (e.g., between 95 and $187 \mathrm{~L} \mathrm{ha}^{-1}$ ). As active ingredient rates (i.e., chemical concentrate) drop due to label or field conditions

(e.g., drop in ground speed), the carrier flow must also be reduced to maintain appropriate dilution ratios. In some cases, a typical fixed orifice nozzle may not provide such turndown ratios; thus, combining the direct injection system with a variable flow nozzle could be a potential solution to this issue.

\section{GOALS AND OBJECTIVES}

The goal of this research was to integrate and evaluate an electronically-actuated variable-flow nozzle with a nozzle direct chemical concentrate injection systems to manage chemical metering in conjunction with carrier flow rate and, ultimately, applied product concentrations. The specific objectives were to: 1) integrate a high-pressure direct nozzle injection system with variable flow carrier control, 2) assess chemical metering accuracy and proper mixing at different combinations of injection valve frequency and duty cycle along with chemical pressure, and 3) assess the ability of the control system to ensure proper chemical dilutions and concentrations in the nozzle effluent resulting from step changes for target application rates based on previous field data collection for a common herbicide.

\section{Materials And Methods}

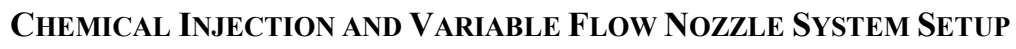

To test the combined direct injection/variable flow nozzle system, a combination of fluorescent red dye (R-0029816, Cole Parmer, Vernon Hills, Ill.), glycerin (99.5\% USP, VEG-BASED, KIC Chemical, Inc., New Poltz, NY), and deionized (DI) water were mixed to simulate the viscosity of a glyphosate solution. To create this solution (henceforth noted as 'chemical' or 'chemical concentrate'), $138.1 \mathrm{~kg}$ of glycerin, $51.1 \mathrm{~kg}$ of DI water, and $94.6 \mathrm{~g}$ of the fluorescent dye were mixed in the vented reservoir. The amount of dye selected ensured a maximum concentration of 2000:1 (Glycerin/DI water to dye ratio) which would allow repeatable absorbance $(A)$ measurements for system validation using a spectrophotometer (SPm) (Luck et al., 2012).

A fixed displacement plunger pump (3XU49, Dayton Electric Manufacturing Co., Lake Forest, Ill.) was driven by a hydraulic motor (101-1749-009, Eaton Corp., Cleveland, Ohio) to supply the chemical concentrate at high pressure. A high-pressure relieving (HPR) valve (6815-1/2, Spraying Systems Co., Wheaton, Ill.) used to adjust and maintain system pressure was placed just upstream of an accumulator $(9.0 \mathrm{~m}$ of $5.08 \mathrm{~cm}$ diameter hydraulic hose) selected to reduce impulses in the chemical from the plunger pump. A 0 to 5 VDC output calibrated pressure transducer (PX309- 
2KG5V, Omegadyne, Inc., Sunbury, Ohio) powered via 12 VDC supply was used to constantly monitor chemical concentrate pressure. A gear flow meter (JVM-12KG, AW-Lake Co., Franksville, Wisc.) with a digital display (RTEx15, AW-Lake Co., Franksville, Wisc.) was placed just upstream of the solenoid valve which supplied the chemical to individual injectors. An 80-mesh inline filter (39908-1, Delavan AgSpray Products, Mendota Heights, Minn.) was placed between the reservoir and pump along with two additional inline filters (9052V-90, Arrow Pneumatics, Broadview, Ill.) installed upstream of the pressure transducer ( $90 \mu \mathrm{m}$ filter) and solenoid valve (10 $\mu \mathrm{m}$ filter). A 24 VDC direct operating solenoid valve (71216SN2BL00N0C111C2, Parker Fluid Control Division, New Britain, Conn.) was placed inline directly ahead of the mixing chamber which was custom fabricated from aluminum. The mixing chamber contained an injection orifice made of brass ( $0.343 \mathrm{~mm}$ diameter); detailed schematics of these two system components can be found in Appendix A of Luck (2012).

The carrier delivery system consisted of a helical rotor pump (101B, Oberdorfer Pumps, Syracuse, N.Y.) driven by a $0.75 \mathrm{hp} 115 \mathrm{VAC}$ motor operating at $1725 \mathrm{rpm}$. A pressure regulating (PR) valve (Model 23120, TeeJet Technologies, Wheaton, Ill.) was used to set and maintain carrier pressure; a 0 to 5 VDC output pressure transducer (PX309-100G5V, Omegadyne, Inc., Sunbury, Ohio) powered via a 12 VDC supply was used to constantly monitor system pressure. An electromagnetic flow meter with a digital display (FMG202-NPT, Omega Engineering, Inc., Stamford, Conn.) was used to monitor carrier flow and provide feedback to the control system. An 80-mesh inline filter (39908-1, Delavan AgSpray Products, Mendota Heights, Minn.) was located between the reservoir and pump. A circuit schematic of the combined chemical injection and carrier delivery systems is shown in Figure 1.

For the purpose of this study, the term 'injector' refers to the combination of the solenoid valve and mixing chamber orifice which were used to control chemical concentrate injection rates. The mixing chamber provided a location where the chemical and carrier could be combined prior to the combined solution exiting through the variable-flow nozzle. The variable-flow nozzle was able to control the flow rates of the mixed solution by increasing and decreasing the size of the nozzle orifice via the electronically-actuated control system. Details regarding the setup and operation of the variable-flow nozzle for carrier flow control were extensively documented by Luck et al. (2015). 

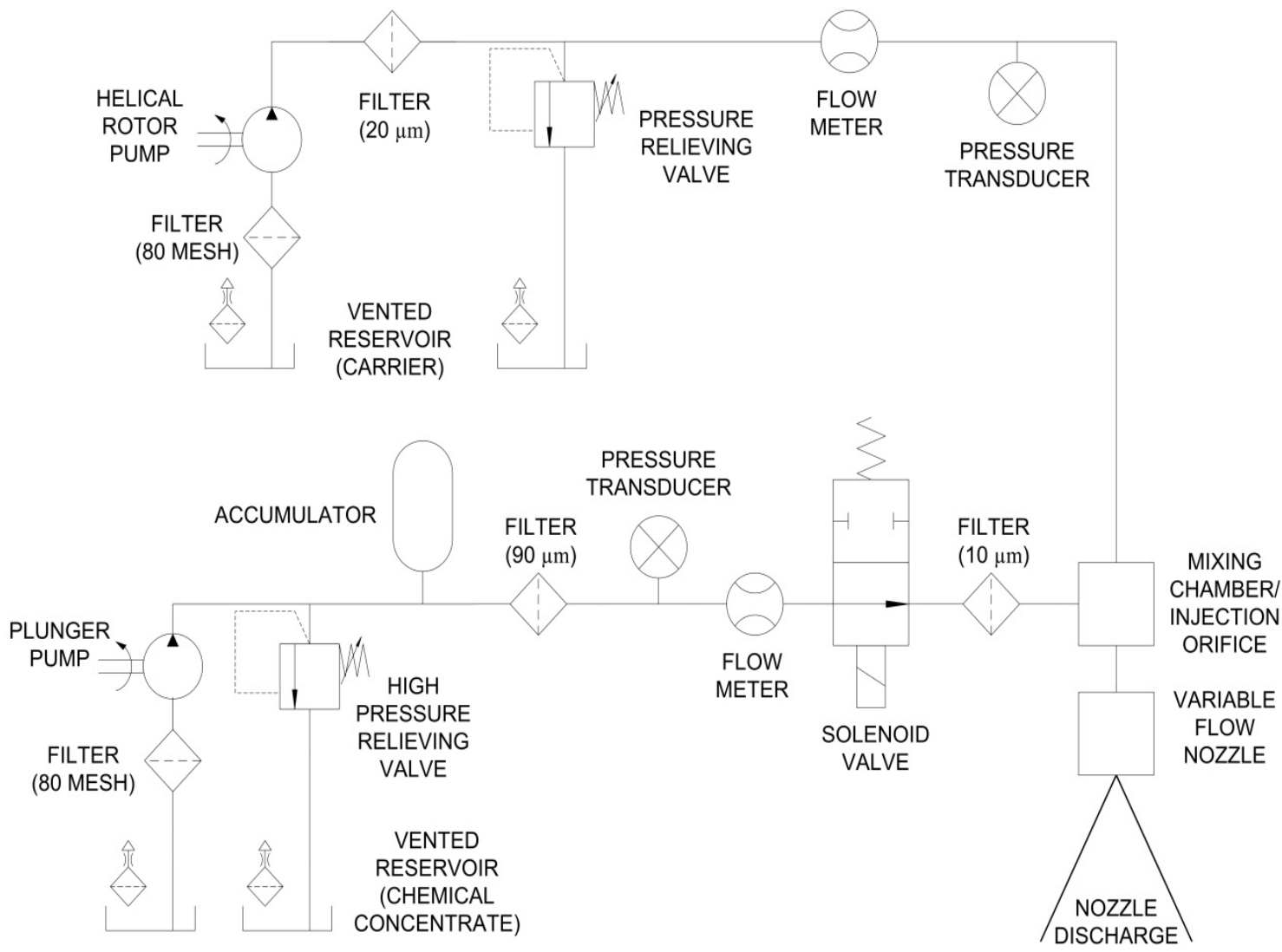

Figure 1: Circuit schematic of combined variable flow nozzle and high-pressure chemical injection system.

The combined system control program for chemical injection (i.e. injector duty cycle $\left(\mathrm{DC}_{\mathrm{i}}\right)$ and frequency) and carrier control can be found in Appendix F of Luck (2012). A USB-based analog and digital I/O data acquisition module (USB-1408FS, Measurement Computing, Inc., Norton, Mass.) connected to a desktop computer was used for data acquisition to record voltage output from the chemical and carrier pressure transducers and the carrier flow meter. The data acquisition module operated in 4-channel differential mode (Measurement Computing, Inc., 2011) to record the desired data and was wired as shown in Figure 2. The dynamic range of the A/D converter was configured to \pm 2.5 $\mathrm{V}$ for channels 2, 3, and 4, and the low input of the A/D channel (terminals 5, 8, and 11) were connected to a $2.5 \mathrm{~V}$ reference voltage supplied by the module to shift the dynamic range to $0-5 \mathrm{~V}$, which matched the output voltage specifications of the chemical pressure transducer and carrier pressure transducers. The carrier flow meter supplied a 4-20 mA signal that was converted to a 1-5 V signal using a $250 \Omega$ resistor.

The control program and data acquisition module also actuated the nozzle effluent sampling system that was used to pass sampling tubes beneath the nozzle. A single digital output was interfaced with a solid-state relay and used to 
start the nozzle effluent sampling system. The sampling tubes were passed approximately $2.5 \mathrm{~cm}$ beneath the nozzle at a constant speed to collect the effluent using the approach developed by Luck (2010). Two different sampling tube sizes (i.e. diameters) were utilized, which (at a constant speed) provided two nozzle effluent sampling rates of 8 and $15 \mathrm{~Hz}$, respectively during test runs. A laser sensor (O1D100, ifm efector, inc., Malvern, PA) was calibrated to measure the location and time (based on the travel speed) as each tube passed beneath the nozzle. The laser sensor produced a 0-10 V output that was fed into channel 1 of the data acquisition module and the module was configured to a dynamic range of $\pm 10 \mathrm{~V}$, resulting in an effective $\mathrm{A} / \mathrm{D}$ resolution of 13 bits.

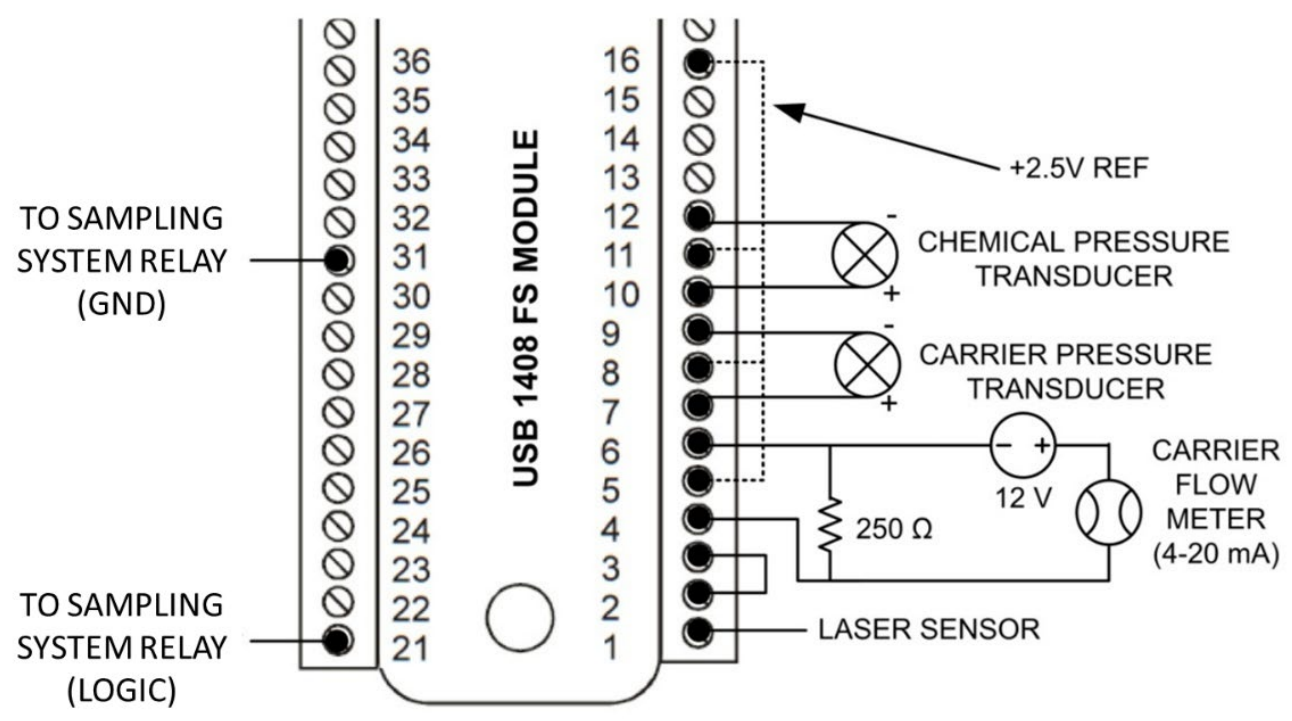

Figure 2: Schematic of data acquisition module setup for chemical concentration tests.

\section{Experimental Procedures ANd Data ANalysis}

\section{Chemical Injection and Metering Evaluation}

The volumetric concentration of a chemical being mixed into solution can be expressed as the chemical volume $\left(\mathrm{V}_{c}\right)$ divided by the total volume of the mixture. For the purposes of this study, ordinary tap water (KAWC, 2010) was used as the carrier, so the chemical concentration $(\varphi)$ was calculated as $V_{c}$ divided by the sum of $V_{c}$ and the volume of water $\left(\mathrm{V}_{\mathrm{w}}\right)$ as shown in Equation 1.

$$
\varphi=\frac{V_{c}}{V_{c}+V_{w}}
$$

Equation 1

A primary goal of spray application systems is to ensure accurate metering (i.e., flow rate) of a chemical or active ingredient, thus Equation 1 was modified to replace $V_{c}$ and $V_{w}$ with flow-based terms that will be useful for this study. Specifically, the chemical concentrate flow rate $\left(\mathrm{Q}_{c}\right)$ and carrier flow rate $\left(\mathrm{Q}_{\mathrm{w}}\right)$ were metered to achieve proper 
application rates and an appropriate amount of carrier for the chemical injection rate. Substitution of $\mathrm{Q}_{\mathrm{c}}$ and $\mathrm{Q}_{\mathrm{w}}$ into Equation 1 gives Equation 2.

$$
\varphi=\frac{Q_{c}}{Q_{c}+Q_{w}} \quad \text { Equation } 2
$$

Equation 2 was rearranged to solve for $\mathrm{Q}_{\mathrm{c}}$ in terms of $\varphi$ and $\mathrm{Q}_{\mathrm{w}}$ in Equation 3. Equation 3 was used to estimate $\mathrm{Q}_{\mathrm{c}}$ which was replaced with $\mathrm{Q}_{\mathrm{c}}^{\prime}$ to indicate that the flow rate was estimated from $\varphi^{\prime}$ (concentration determined from spectrophotometer-based absorbance measurements) and $\mathrm{Q}^{\prime}{ }_{\mathrm{w}}$ measured from the carrier flow meter.

$$
Q_{c}^{\prime}=\frac{\varphi^{\prime} * Q_{w}^{\prime}}{\left(1-\varphi^{\prime}\right)} \quad \text { Equation } 3
$$

The chemical injector was calibrated at $2.76 \mathrm{MPa}$ with an operating frequency of $5 \mathrm{~Hz}$ to develop a flow $\left(\mathrm{Q}_{\mathrm{i}}\right)$ versus $\mathrm{DC}_{\mathrm{i}}$ relationship for the injector based on Equation 4 from Luck et al. (2016) shown here as Equation 4.

$$
Q_{i}=a_{i} D C_{i}+b_{i} \quad \text { Equation } 4
$$

where

$a_{i}=$ calibration slope constant for injector $i$,

$b_{i}=$ calibration intercept slope for injector $i$.

An operating pressure of $0.28 \mathrm{MPa}$ was chosen for the carrier flow. The Hagen-Poiseuille equation states that the flow through the orifice is proportional to the change in pressure $(\Delta \mathrm{P})$ across the orifice. Thus, the chemical system pressure was increased to $3.04 \mathrm{MPA}$ (after having been calibrated at $2.76 \mathrm{MPa}$ ) via the HPR valve to maintain a constant $\Delta \mathrm{P}$ which accounted for the carrier pressure in the injection manifold. The carrier pump was started and $\mathrm{Q}_{\mathrm{w}}$ was recorded at a frequency of $15 \mathrm{~Hz}$ and saved to a text file during each test. The injector was set to a specific $\mathrm{DC}_{\mathrm{i}}$ using the control program. The output (pulses) from the chemical flow meter were recorded during each test along with the total time of injector operation at the constant $\mathrm{DC}_{\mathrm{i}}$. It should be noted that the chemical flow meter was only accurate for a set $\mathrm{DC}_{\mathrm{i}}$, as it was affected by pulses in the liquid. Therefore, a calibration (pulses $/ \mathrm{mL}$ ) was found for a particular $\mathrm{DC}_{\mathrm{i}}$, but varied across the range of $10 \%$ to $90 \% \mathrm{DC}_{\mathrm{i}}$. During each injector calibration, the pulses per $\mathrm{mL}$ were noted for each $\mathrm{DC}_{\mathrm{i}}$ setting. The standard error involved with using the flow meter to predict the chemical flow was estimated at $2.7 \%$.

The solution from each sampling tube was poured into a $1 \mathrm{~mL}$ cuvette and tested using an Evolution 60 spectrophotometer (SPm) (Thermo Scientific, 2007) according to the methods outlined by Luck et al. (2012). All tests were conducted in the laboratory at a temperature of approximately $19^{\circ} \mathrm{C}$. A calibration curve to determine $\varphi^{\prime}$ from 
SPm absorbance $(A)$ measurements was also developed prior to testing using the methods discussed by Luck et al. (2012). The chemical concentrate was diluted in DI water to $\varphi$ values of 0.001 , and replicated $A$ measurements were taken for each dilution. The relationship of $\varphi$ to $A$ was then plotted and a trend line was fit to these data to determine the calibration equation. Using this information, it was possible to predict $\varphi^{\prime}$ for each $A$ value measured from the samples. The $\mathrm{Q}^{\prime}{ }_{\mathrm{w}}$ was estimated from the carrier flow meter output while operating the injection system. $\mathrm{Q}_{\mathrm{c}}^{\prime}$ was then calculated using Equation 3 with the value of $\mathrm{Q}^{\prime}{ }_{\mathrm{w}}$ corresponding to the average sample $\varphi^{\prime}$ collected from the nozzle effluent.

To determine the accuracy of the injection system, $\mathrm{Q}_{\mathrm{c}}{ }_{\mathrm{c}}$ was compared to $\mathrm{Q}_{\mathrm{c}}$ estimated from the chemical flow meter. The error between these two values (calculated as the difference between the two, divided by $\mathrm{Q}_{\mathrm{c}}$ ) provided an estimate of accuracy for the chemical injection system. The purpose of these tests was to evaluate mixing of the chemical prior to exiting the nozzle, thus frequency spectra plots were developed in MATLAB using the discrete Fourier transform function $f f t($ ). Frequency spectra plots of the allowed for visual inspection of any embedded frequencies (i.e. the injection frequency) in the absorbance measurements from the effluent collected in the sampling tubes. These tests were observed at DCi settings of 10\%, 50\%, and 90\% at chemical pressures of $3.04 \mathrm{MPa}(5 \mathrm{~Hz})$ and $5.87 \mathrm{MPa}(7 \mathrm{~Hz})$.

\section{Chemical Concentration Accuracy Evaluation}

Successful chemical application requires both accurate metering of the active ingredient rates and maintenance of appropriate dilutions of the chemical in the carrier. To accomplish proper chemical-to-carrier dilutions, Equation 2 was rearranged to calculate the desired carrier flow rate $\left(\mathrm{Q}_{\mathrm{w}}\right)$ based on the current $\mathrm{Q}_{\mathrm{c}}$ and the desired $\varphi$, as shown in Equation 5.

$$
Q_{w}=\left(\frac{Q_{c}}{\varphi}\right)-Q_{c}
$$

Equation 5

Therefore, the desired $\mathrm{Q}_{\mathrm{w}}$ could be directly calculated in terms of the current $\mathrm{DC}_{\mathrm{i}}$ by substituting Equation 4 into Equation 5. This method yielded Equation 6 to calculate the desired $Q_{w}$ based on $a_{i}$ and $b_{i}$ (for injector i) with $\mathrm{DC}_{i}$ and $\varphi$.

$$
Q_{w}=\left(\frac{a_{i} D C_{i}+b_{i}}{\varphi}\right)-a_{i} D C_{i}+b_{i} \quad \text { Equation } 6
$$

Equation 6 was integrated into the control program to provide the nozzle with a desired $\mathrm{Q}_{\mathrm{w}}$ based on the current target chemical injection rate. The minimum and maximum $\mathrm{DC}_{\mathrm{i}}$ settings used in this study were $10 \%$ and $90 \%$, respectively. 
Initial calibration of the injector provided $a_{i}$ and $b_{i}$ values for Equation $6 . \mathrm{DC}_{\mathrm{i}}$ was selected based on field application scenario and the glyphosate product label (Monsanto, 2002), respectively. The field application scenario was chosen based on the data the average field velocity from the case study by Luck et al. (2011) which was $5.56 \mathrm{~m} / \mathrm{s}$, with a standard deviation of $1.55 \mathrm{~m} / \mathrm{s}$, at a nozzle spacing of $0.51 \mathrm{~m}$. Therefore, the desired $\mathrm{Q}_{\mathrm{c}}$ was selected to achieve an application rate of $4.7 \mathrm{~L} / \mathrm{ha}$ (chemical) for a velocity of $5.56 \mathrm{~m} / \mathrm{s} \pm 1.55 \mathrm{~m} / \mathrm{s}$ and the injector operating at $5.87 \mathrm{MPa}$ at a frequency of $7 \mathrm{~Hz}$. Thus, four step response scenarios were chosen, with $\mathrm{DC}_{\mathrm{i}}$ step changes of $23 \%$ to $16 \%, 30 \%$ to $16 \%, 23 \%$ to $30 \%$, and $16 \%$ to $30 \%$. These increases and decreases were meant to mirror increases and decreases in target flow rates based on those field actual field data.

The desired $\varphi$ was determined from the glyphosate product label (Monsanto, 2002). According to the label, 0.71 to $1.9 \mathrm{~L}$ of glyphosate may be mixed with 37.9 to $75.7 \mathrm{~L}$ of water. The resulting minimum and maximum $\varphi$ of chemical to carrier would therefore be 0.0093 to 0.0476 , respectively. Maximizing the $\varphi$ would result in the minimal use of water. Therefore, the desired $\varphi$ was selected as 0.03614 , which would provide for some water conservation while allowing room for error prior to exceeding the maximum allowable $\varphi$. The settling time $\left(\mathrm{t}_{\mathrm{s}}\right)$ and average steady state error $\left(e_{s s}\right)$ of the system were evaluated as discussed by Luck et al. (2015). The $t_{s}$ was calculated for values of $Q_{c}$ upon reaching $\pm 5 \%$ of $\mathrm{Q}_{\mathrm{w}}$. After the $\mathrm{t}_{\mathrm{s}}$ had been achieved, the absolute difference between $\mathrm{Q}_{\mathrm{c}}$ values and $\mathrm{Q}_{\mathrm{w}}$ were averaged (up until the next step input) to determine the value of ess. Values of $t_{s}$ were calculated as the time when $\mathrm{Q}_{\mathrm{w}}$ was set until values of $\mathrm{Q}_{c}$ reached and were maintained at $\mathrm{Q}_{\mathrm{w}} \pm 5 \%$.

\section{RESULTS AND DISCUSSION}

\section{ChEMICAL INJECTION AND METERING TEST RESUlts}

Prior to any system tests, it was necessary to determine the calibration equation for estimating $\varphi^{\prime}$ based on $A$ measurements from the SPm. The calibration was carried out (Figure 3) to determine this relationship and the linear regression equation was noted. This calibration equation determined using this method was used for all chemical metering tests and concentration accuracy tests. 


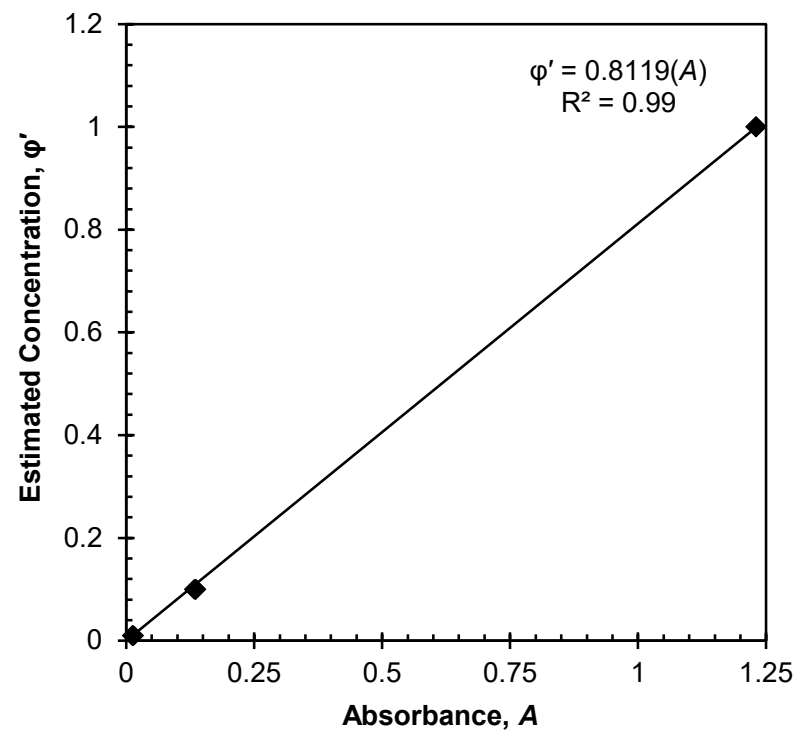

Figure 3: Estimated concentration $\left(\varphi^{\prime}\right)$ versus absorbance (A) for the chemical concentrate diluted in DI water.

Thus, the calibration equation for estimating $\varphi^{\prime}$ based on measurements of $A$ from the SPm is shown in Equation 7. The range of test $A$ values were fully bound by the calibration data in Figure 3, therefore, extrapolation of $\varphi^{\prime}$ values was unnecessary.

$$
\varphi^{\prime}=0.8199(A) \quad \text { Equation } 7
$$

Figure 4 shows the calibration for $\mathrm{Q}_{\mathrm{i}}$ versus $\mathrm{DC}_{\mathrm{i}}$ with the injector operating at $2.76 \mathrm{MPa}$ and $5 \mathrm{~Hz}$ which included three replicates collected at 10\%, 50\%, and 90\% DC. As previously discussed, the flow meter output was 19.7, 11.1, and 9.0 pulses $/ \mathrm{mL}$ for $\mathrm{DC}_{\mathrm{i}}$ values of $10 \%, 50 \%$, and $90 \%$, respectively. While the flow meter output varied greatly across the range of $\mathrm{DC}_{\mathrm{i}}$ values tested, the calibration (pulses $/ \mathrm{mL}$ ) was rather repeatable for a set $\mathrm{DC}_{\mathrm{i}}$. The data in Figure 4. also reinforced the linear relationship between $\mathrm{DC}_{\mathrm{i}}$ and $\mathrm{Q}_{\mathrm{i}}$ for the injection system, as discussed by Luck et al. (2016). 


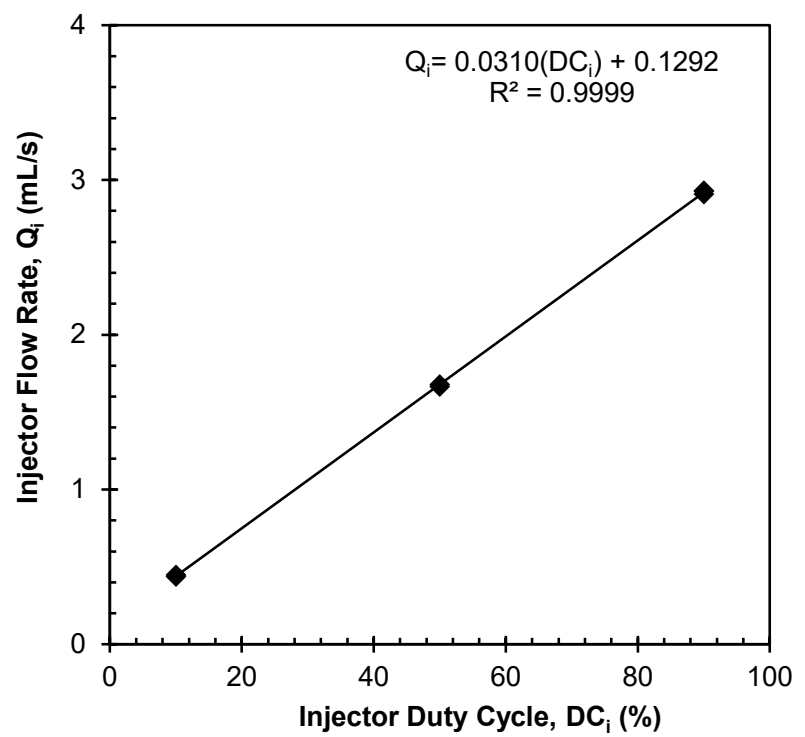

Figure 4: Calibration equation for injector flow rate (Qi) versus duty cycle (DCi) at 2.76 MPa and $5 \mathrm{~Hz}$.

As mentioned in the previous section, the chemical injection pressure was increased to $3.04 \mathrm{MPa}$ to compensate for the additional manifold pressure from the carrier. It should be noted, that while the injection pressure increased, the same calibration equation (Figure 4) was used, as the value of $\Delta \mathrm{P}$ through the orifice equaled $2.76 \mathrm{MPa}$. Table 1 contains a summary of the data collected for comparing the $\mathrm{Q}_{\mathrm{c}}$ (from the flow meter) to $\mathrm{Q}_{\mathrm{c}}$ (from the absorbance data). The overall error between $\mathrm{Q}_{c}$ and $\mathrm{Q}_{c}^{\prime}$ was $5.7 \%$ for these tests. The average error was higher than desired values $(<5 \%)$, however these data represented promising results for chemical metering considering the potential contribution to error from sources including the chemical flow meter, carrier flow meter, and SPm.

Table 1: Summary of test results comparing $Q_{c}$ (from flow meter) versus $Q_{c}^{\prime}$ (from absorbance data).

\begin{tabular}{cccccc}
\hline $\begin{array}{c}\mathrm{DC}_{\mathrm{i}} \\
(\%)\end{array}$ & $\begin{array}{c}\mathrm{Q}_{\mathrm{c}} \\
(\mathrm{mL} / \mathrm{s})\end{array}$ & $\varphi^{\prime}$ & $\begin{array}{c}\mathrm{Q}^{\prime}{ }_{\mathrm{w}} \\
(\mathrm{mL} / \mathrm{s})\end{array}$ & $\begin{array}{c}\mathrm{Q}_{\mathrm{c}}^{\prime} \\
(\mathrm{mL} / \mathrm{s})\end{array}$ & $\begin{array}{c}\text { Error } \\
(\%)\end{array}$ \\
\hline 50 & 1.67 & 0.0349 & 43.78 & 1.58 & 5.4 \\
50 & 1.64 & 0.030 & 56.59 & 1.73 & 5.5 \\
50 & 1.61 & 0.0372 & 44.83 & 1.73 & 7.5 \\
50 & 1.68 & 0.026 & 56.17 & 1.51 & 9.8 \\
90 & 2.91 & 0.051 & 54.91 & 2.96 & 1.7 \\
90 & 2.96 & 0.052 & 51.96 & 2.87 & 2.8 \\
90 & 2.96 & 0.138 & 19.89 & 3.18 & 7.6 \\
\hline
\end{tabular}

The error appeared to decrease at $90 \% \mathrm{DC}_{\mathrm{i}}\left(4 \%\right.$ average) compared to the $50 \% \mathrm{DC}_{\mathrm{i}}$ setting $(7 \%$ average), which is typical for such systems that utilize pulse-width modulation (PWM) for flow control at lower $\mathrm{DC}_{\mathrm{i}}$ settings. As flow rates decrease, it is often the case that measurement errors increase from such flowmeters; novel systems to reduce this error would be worth research efforts in the future. Overall, these results indicate the potential for accurate metering of the chemical concentrate based on open-loop operation of the injector. These data also show that continual 
calibration of the system would be critical for successful applications as discussed by Luck et al. (2016) due to changing fluid viscosities.

The nozzle effluent concentration data were then analyzed to determine the effects of injection pressure and operating frequency on mixing of the chemical prior to exiting the nozzle. This was accomplished by computing the power spectral density of the $A$ data collected at $15 \mathrm{~Hz}$. The fast Fourier transform (fft) Matlab function used for this analysis allowed for identification of embedded frequencies in the $A$ data from the sampling tubes up to $7.5 \mathrm{~Hz}$ (half the sampling frequency).

The first test was conducted with the injector operating at $90 \% \mathrm{DC}_{\mathrm{i}}, 3.04 \mathrm{MPa}$, and $5 \mathrm{~Hz}$, with the carrier pressure set at $0.28 \mathrm{MPa}$. The power spectral density plot (Figure 5) indicated no frequency component in the $A$ data at $5 \mathrm{~Hz}$. The results shown in Figure 5 were not surprising considering the injector was pulsed at $90 \% \mathrm{DC}_{\mathrm{i}}$, essentially open constantly. Because the solenoid was open $90 \%$ of each pulse, adequate mixing normal to the direction of travel for the nozzle was expected at this $\mathrm{DC}_{\mathrm{i}}$. Mechanical limitations of the solenoid meant that flow was assumed to be nearly constant through the orifice during testing at this high of a $\mathrm{DC}_{\mathrm{i}}$. In the subsequent tests, with the injector pulsed at $50 \% \mathrm{DC}_{\mathrm{i}}$ (at the same operating pressure), the frequency component at $5 \mathrm{~Hz}$ was identified by the power spectral density analysis Figure 5. Figure 5 illustrates the spectral density data as the $\mathrm{DC}_{\mathrm{i}}$ was changed to $20 \%$ while operating at $3.04 \mathrm{MPa}$ and $5 \mathrm{~Hz}$. As expected, the frequency component of the $A$ data is again noticeable at the $5 \mathrm{~Hz}$ injection frequency.

These data provide evidence that inadequate mixing may have occurred in the mixing chamber at the $50 \%$ and $20 \%$ $\mathrm{DC}_{\mathrm{i}}$ settings. There are several potential sources for this, including operational characteristics of the injector (i.e., pressure, frequency, $\mathrm{DC}_{\mathrm{i}}$ ), mixing chamber size, or carrier flow rate. These data also indicate that depending on the operational characteristics of the injector and nozzle for carrier delivery, proper sampling techniques should be observed. Injector operation in this scenario $(3.04 \mathrm{MPa}, 5 \mathrm{~Hz})$ required twice the sampling rate of the injection frequency to identify if 'pulses' could be identified in the chemical/carrier signal. As the $\mathrm{DC}_{\mathrm{i}}$ decreased toward $50 \%$, the injection frequency component was clearly noticeable. Thus, further analysis to determine the error in the mixed solution may be helpful, clearly at the set pressure and frequency, improper mixing was noted in the $A$ measurements. 
a)

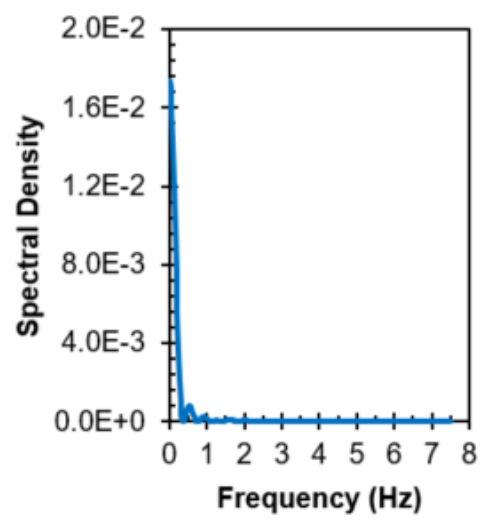

b)

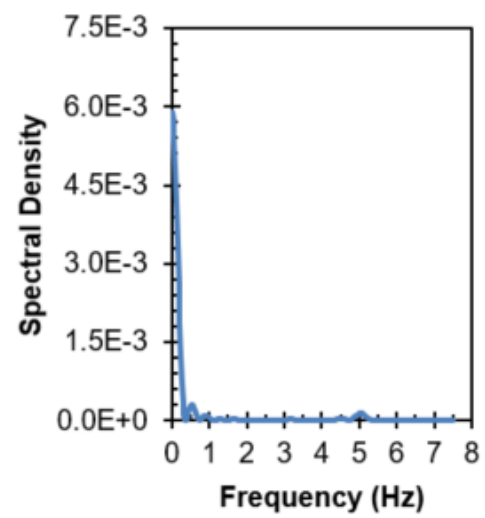

c)

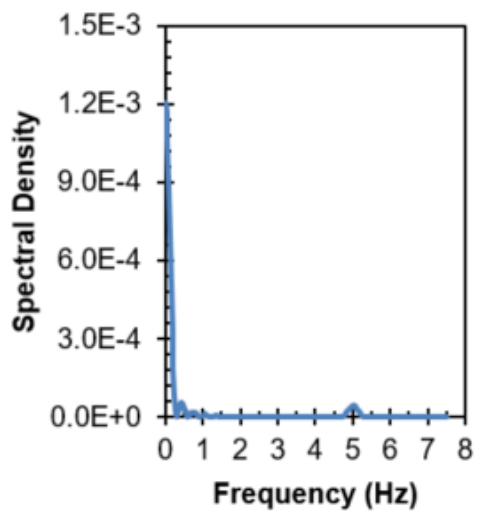

Figure 5: Frequency analysis of estimated chemical concentration sampled at $15 \mathrm{~Hz}$ for injector duty cycles $\left(\mathrm{DC}_{\mathrm{i}}\right) \mathrm{of}$ a) $90 \%$, b) $50 \%$, and c) 20\% at 3.04 MPa chemical pressure, $5 \mathrm{~Hz}$ injection frequency, and $0.28 \mathrm{MPa}$ carrier pressure.

To evaluate if injection pressure and/or operating frequency could have some effect on mixing of the chemical, an additional test was conducted with the injector at $5.87 \mathrm{MPa}$ and $7 \mathrm{~Hz}$, with the carrier pressure set at $0.35 \mathrm{MPa}$. Three $\mathrm{DC}_{\mathrm{i}}$ settings were chosen for these tests; $20 \%, 50 \%$, and $90 \% \mathrm{DC}_{\mathrm{i}}$. The carrier pressure was slightly increased in this case to maintain similar expected values of $A$ in the nozzle effluent.

The power spectral density for the injector at $90 \% \mathrm{DC}_{\mathrm{i}}$ is shown in Figure 6. There were no indications that the injection frequency affected $A$ measurements, and thus mixing of the nozzle effluent. Power spectral density results were similar when the injection $\mathrm{DC}_{\mathrm{i}}$ was reduced to $50 \%$ and $20 \%$ as there were no frequency components identified in the analysis near the injection frequency of $7 \mathrm{~Hz}$ Figure 6.

These results show that the injection pressure and frequency affected chemical mixing in the manifold. Injection pressure most likely contributed most to the improved mixing of the chemical prior to exiting the nozzle. The carrier rate was slightly increased when the injector pressure increased; however, this would likely have reduced mixing efficiency for the system. Reduced carrier flow rates would provide additional residence (mixing) time for the chemical and carrier to mix in the manifold prior to discharge.

This occurrence illustrates the challenge in developing an optimized system. Increased residence times (e.g., increasing mixing chamber size or decreasing carrier flow rate) would typically result in a slower system response and higher system lag times. Another problem associated with this issue is that proper carrier flow rates must be maintained to ensure that chemical concentrations in the carrier are not off-label. This issue will be addressed in the next section. 
a)

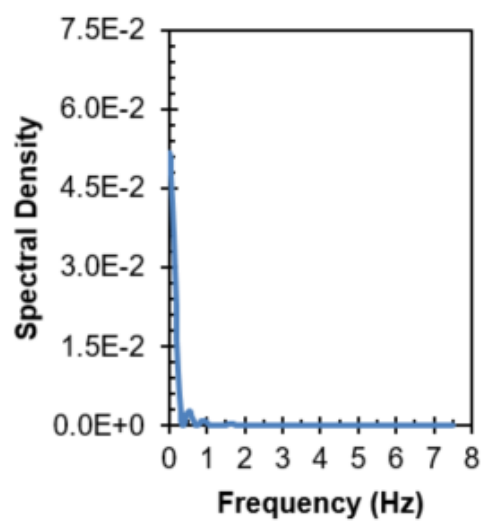

b)

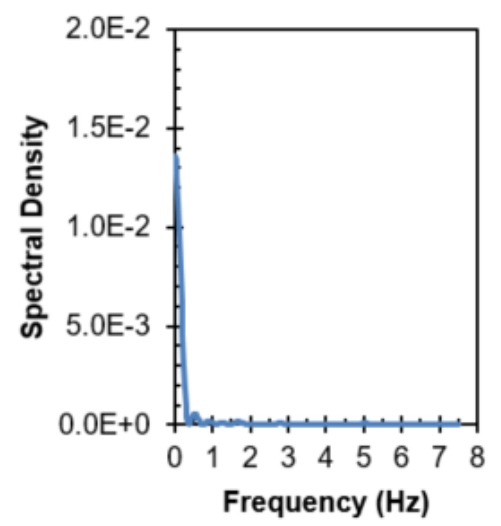

c)

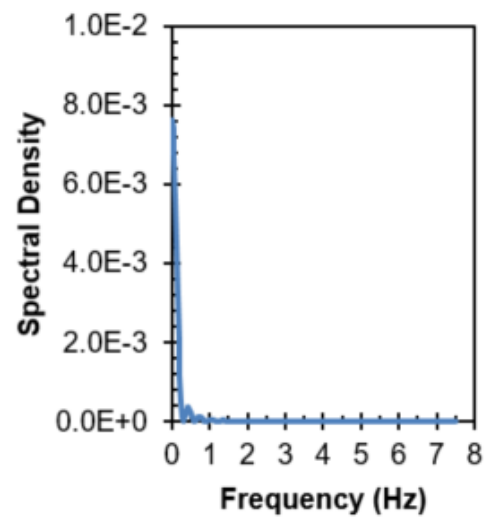

Figure 6: Frequency analysis of estimated chemical concentration sampled at $15 \mathrm{~Hz}$ for injector duty cycles $(\mathrm{DC}$ ) of a) $90 \%$, b) $50 \%$, and c) $20 \%$ at 5.87 MPa chemical pressure, $7 \mathrm{~Hz}$ injection frequency, and $0.35 \mathrm{MPa}$ carrier pressure.

\section{Chemical Concentration ACCuracy Test Results}

Figure 7 illustrates the calibration for $\mathrm{Q}_{\mathrm{i}}$ versus $\mathrm{DC}_{\mathrm{i}}$ with the injector operating at $5.52 \mathrm{MPa}$ and $7 \mathrm{~Hz}$ which included three measurements collected at $10 \%, 50 \%$, and $90 \% \mathrm{DC}_{\mathrm{i}}$. This calibration provided the $\mathrm{a}_{\mathrm{i}}$ and $\mathrm{b}_{\mathrm{i}}$ values to estimate the current injection rate (with $\varphi$ ) using Equation 6. The injection pressure was increased to 5.87 MPa to compensate for the carrier pressure in the mixing chamber $(0.35 \mathrm{MPa})$ during tests. The objective of this set of tests was to evaluate the ability of the variable flow nozzle developed by Luck et al. (2015a) to maintain proper carrier flow rates for appropriate $\varphi$ levels.

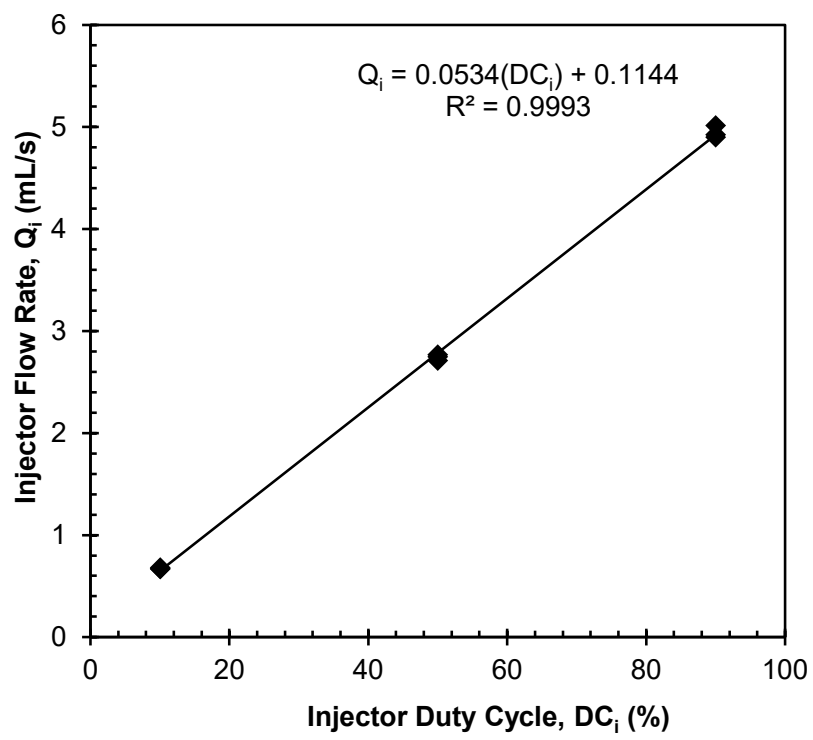

Figure 7: Step response calibration equation for injector flow rate (Qi) versus duty cycle (DCi) at 5.52 MPa and $7 \mathrm{~Hz}$. 
Figure 8 shows the $\varphi^{\prime}$ and $\mathrm{Q}^{\prime}{ }_{\mathrm{w}}$ data collected as the $\mathrm{DC}_{\mathrm{i}}$ was decreased from $23 \%$ to $16 \%$ at $1.25 \mathrm{~s}$. The effect of the reduced $\mathrm{Q}_{\mathrm{c}}$ is evident as the $\varphi^{\prime}$ levels dropped to 0.0184 shortly after the step; however, the nozzle was able to recover to the desired flow rate $( \pm 5 \%)$ within $0.88 \mathrm{~s}$. While the minimum $\varphi^{\prime}$ value $(0.0184)$ was substantially less than the desired value (0.03614), the minimum dilution (0.0093) from the product label was not exceeded. During this test, the maximum $\varphi^{\prime}$ recorded was 0.0399 , which did not exceed maximum allowable concentration levels of 0.0476 .

The value of $\mathrm{t}_{\mathrm{s}}(0.88 \mathrm{~s})$ was similar to that noted by Luck et al. (2015a) for the nozzle operating without the injection system. This indicated that the performance of the nozzle was not affected by the presence of the injected fluid in the manifold. The average $\mathrm{e}_{\mathrm{ss}}$ after the effluent reached the desired $\varphi^{\prime}( \pm 5 \%)$ was $2.9 \%$. Therefore, for low injection rates $\left(16 \% \mathrm{DC}_{\mathrm{i}}\right.$ in this case), the nozzle was able to provide appropriate carrier flow rates with minimal error.

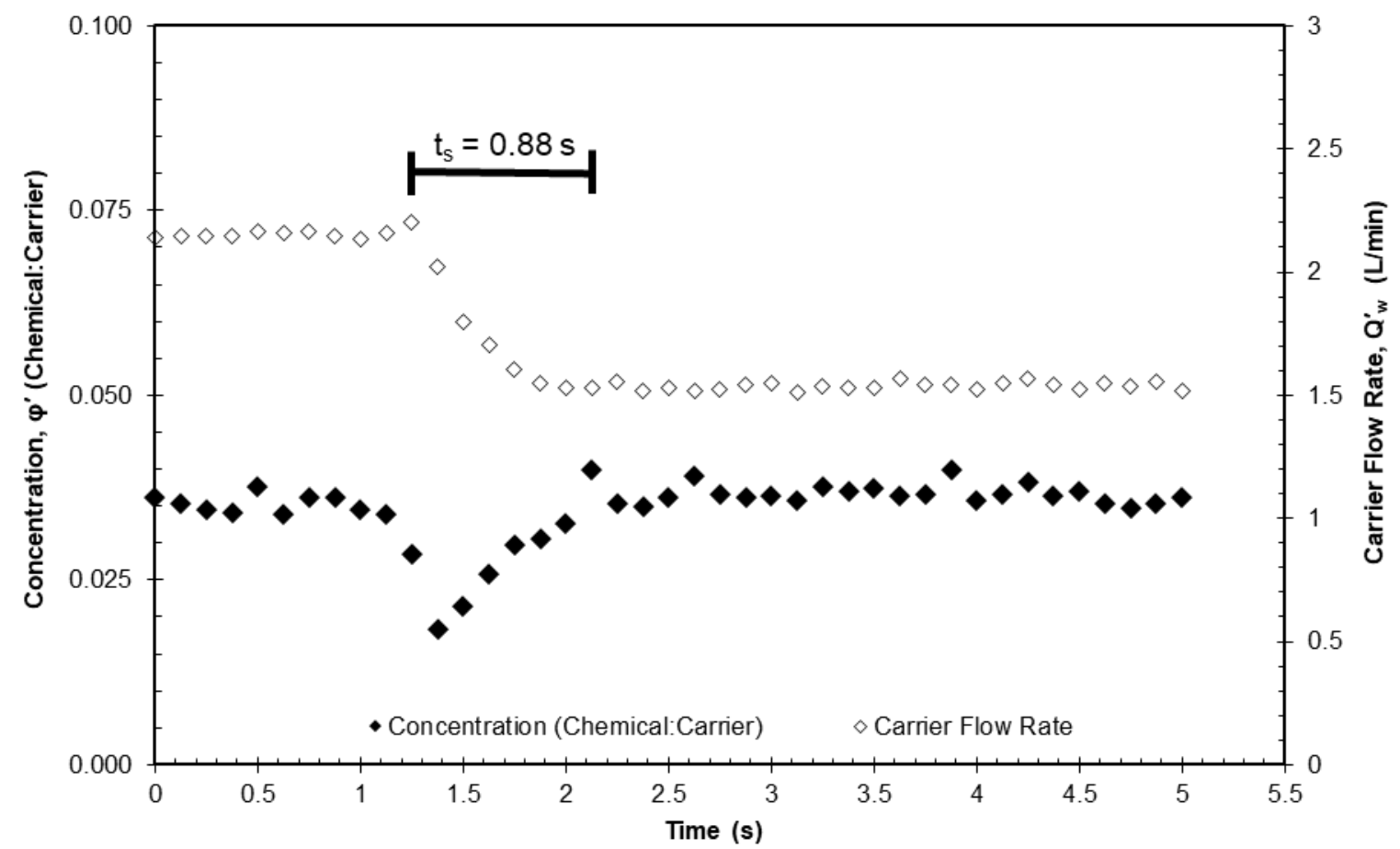

Figure 8: Chemical concentration $\left(\varphi^{\prime}\right)$ and carrier flow rate $\left(Q^{\prime} w\right)$ step-response results for a $\mathrm{DCi}$ change of $23 \%$ to $16 \%$ at 1.25 s (carrier at $0.35 \mathrm{MPa}$; injector operated at $5.87 \mathrm{MPa}$ and $7 \mathrm{~Hz}$ ).

Figure 9 shows the $\varphi^{\prime}$ and $\mathrm{Q}^{\prime}{ }_{\mathrm{w}}$ step response data collected as the injector $\mathrm{DC}_{\mathrm{i}}$ was changed from $16 \%$ to $30 \%$ at $1.25 \mathrm{~s}$. The maximum $\varphi^{\prime}$ reached 0.0467 which was higher than the desired value $(0.03614)$ and nearly exceeded the maximum dilution (0.0476) from the product label. The nozzle was able to quickly recover to the desired flow rate within $0.625 \mathrm{~s}$. The minimum $\varphi^{\prime}$ recorded was 0.0304 , which was within allowable concentration levels. 
The value of $\mathrm{t}_{\mathrm{s}}$ was slightly less than the step from $23 \%$ to $16 \% \mathrm{DC}_{\mathrm{i}}$ which was likely due to the movement of the metering stem in the direction of carrier pressure force on the diaphragm. The average $\mathrm{e}_{\mathrm{ss}}$ after the effluent reached the desired $\varphi^{\prime}( \pm 5 \%)$ was $7.5 \%$. While this could be problematic for sustained errors in terms of application rates, an error of this magnitude in $\varphi$ is probably not as important since a wide range of chemical-to-carrier concentrations was available. An optimal scenario, however, might be to minimize carrier usage during field applications.

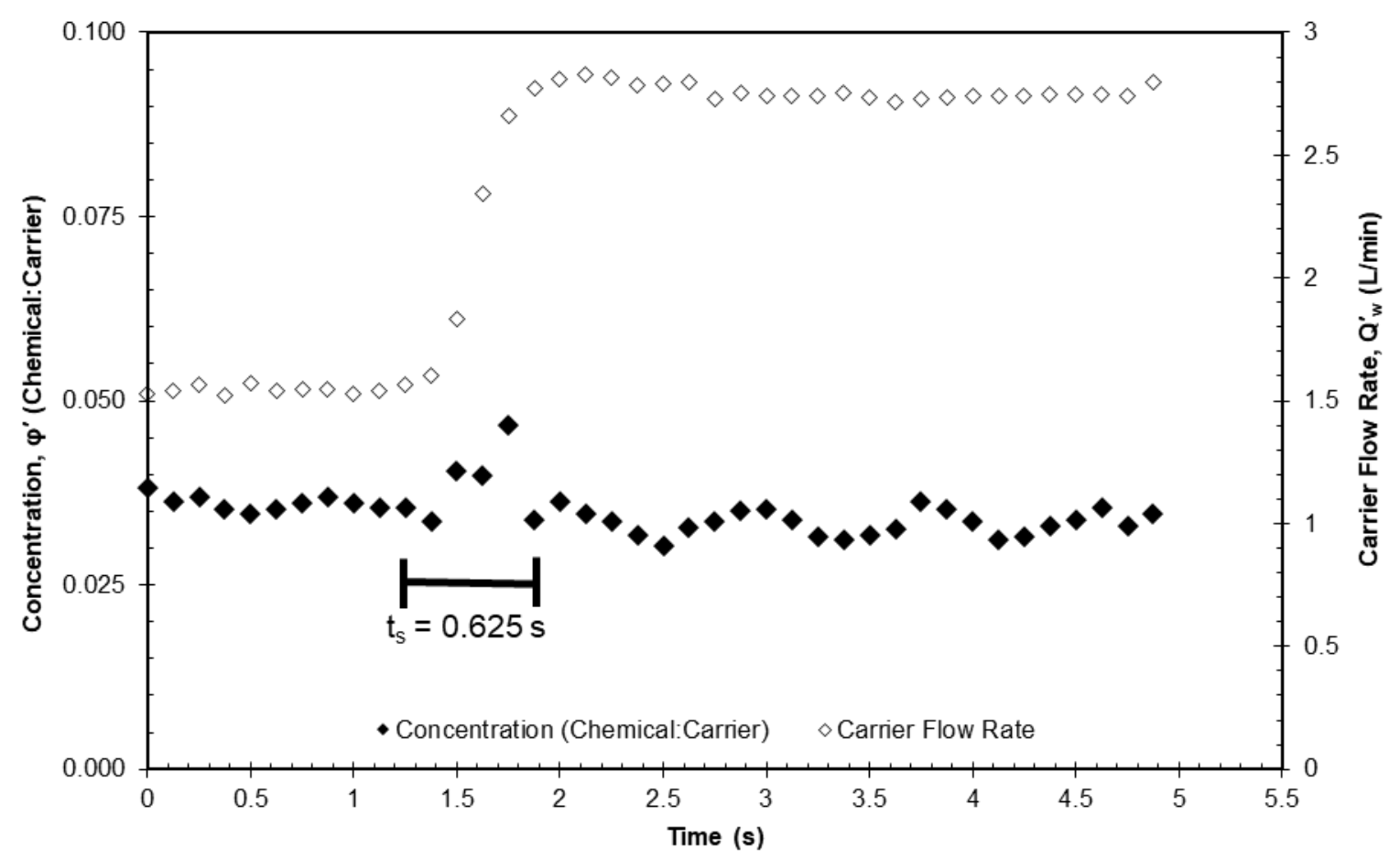

Figure 9: Chemical concentration $\left(\varphi^{\prime}\right)$ and carrier flow rate $\left(Q^{\prime} w\right)$ step-response results for a $\mathrm{DCi}$ change of $16 \%$ to $30 \%$ at $1.25 \mathrm{~s}$ (carrier at 0.35 MPa; injector operated at 5.87 MPa and $7 \mathrm{~Hz}$ ).

Figure 10 shows the $\varphi^{\prime}$ and $\mathrm{Q}^{\prime}{ }_{\mathrm{w}}$ step response data for the injector $\mathrm{DC}_{\mathrm{i}}$ from $23 \%$ to $30 \%$ at $1.25 \mathrm{~s}$. The maximum $\varphi^{\prime}$ reached 0.0562 which exceeded the maximum allowable $\varphi(0.0476)$ from the product label. However, the nozzle was able to bring the $\varphi^{\prime}$ levels below the maximum allowable value within $0.5 \mathrm{~s}$. The minimum $\varphi^{\prime}$ recorded was 0.0309 , which was within allowable concentration levels. The value of $t_{s}$ of $0.63 \mathrm{~s}$ was similar to that for the step from $16 \%$ to $30 \% \mathrm{DC}_{\mathrm{i}}$ which was likely attributed to the movement direction of the metering stem. The average $\mathrm{e}_{\mathrm{ss}}$ after the effluent reached the desired $\varphi^{\prime}( \pm 5 \%)$ was $6.6 \%$ which was similar to the previous step to a higher $\mathrm{DC}_{\mathrm{i}}$.

The final step response data as the injector $\mathrm{DC}_{\mathrm{i}}$ was changed from $30 \%$ to $16 \%$ (at $1.25 \mathrm{~s}$ ) are shown in Figure 11. The maximum $\varphi^{\prime}$ reached 0.0394 which did not exceed the maximum $\varphi(0.0476)$ from the product label. The minimum $\varphi^{\prime}$ recorded for these data was 0.0249 , which was within the allowable range. The value of $t_{\mathrm{s}}$ of $1.0 \mathrm{~s}$ was 
similar to that for the step from $23 \%$ to $16 \%$. The average $\mathrm{e}_{\mathrm{ss}}$ after the effluent reached the desired $\varphi^{\prime}( \pm 5 \%)$ was $2.5 \%$, similar to the previous test where $\mathrm{DC}_{\mathrm{i}}$ was decreased.

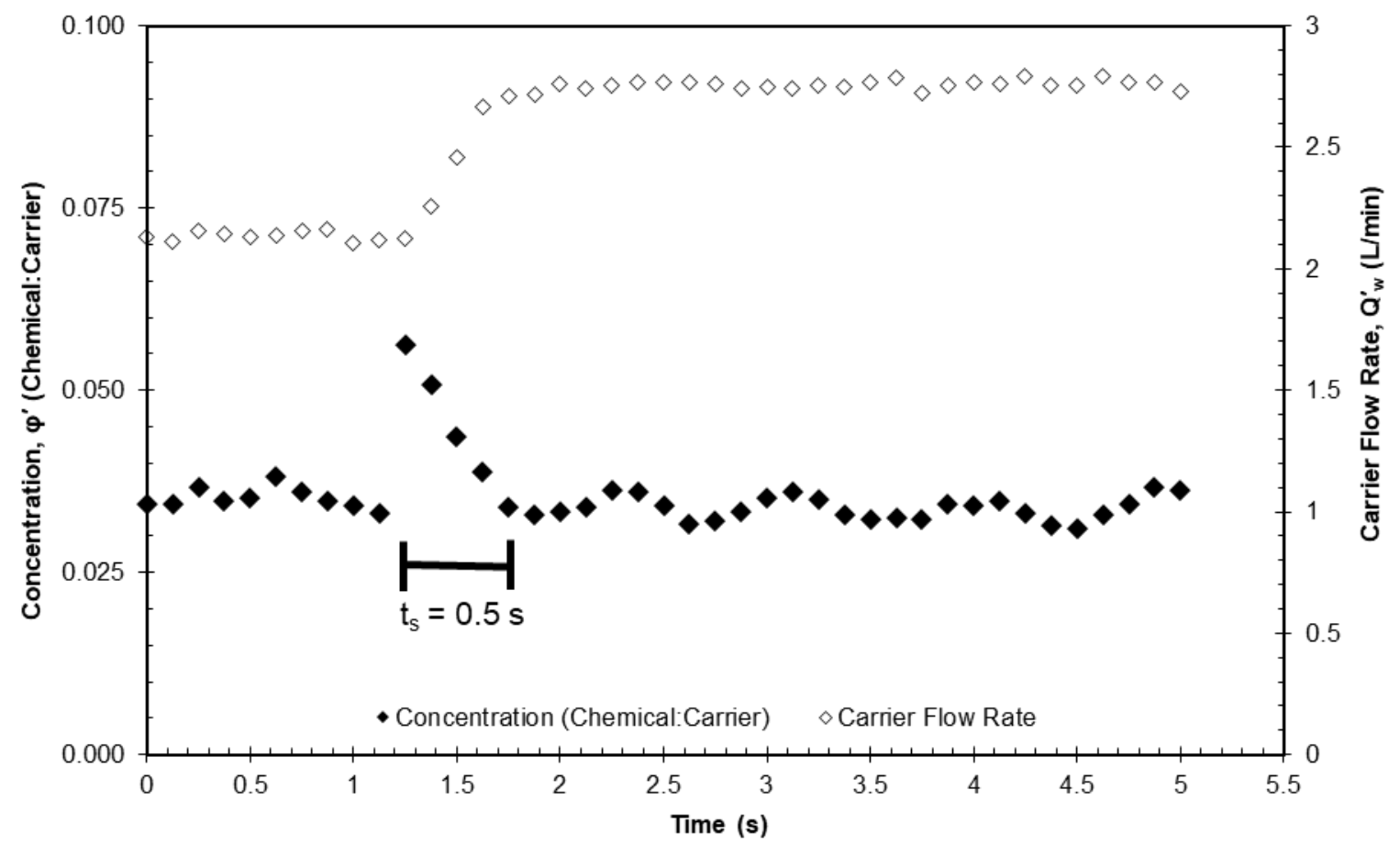

Figure 10: Chemical concentration $\left(\varphi^{\prime}\right)$ and carrier flow rate $\left(Q^{\prime} w\right)$ step-response results for a DCi change of $23 \%$ to $30 \%$ at $1.25 \mathrm{~s}$ (carrier at 0.35 MPa; injector operated at 5.87 MPa and $7 \mathrm{~Hz}$ ). 


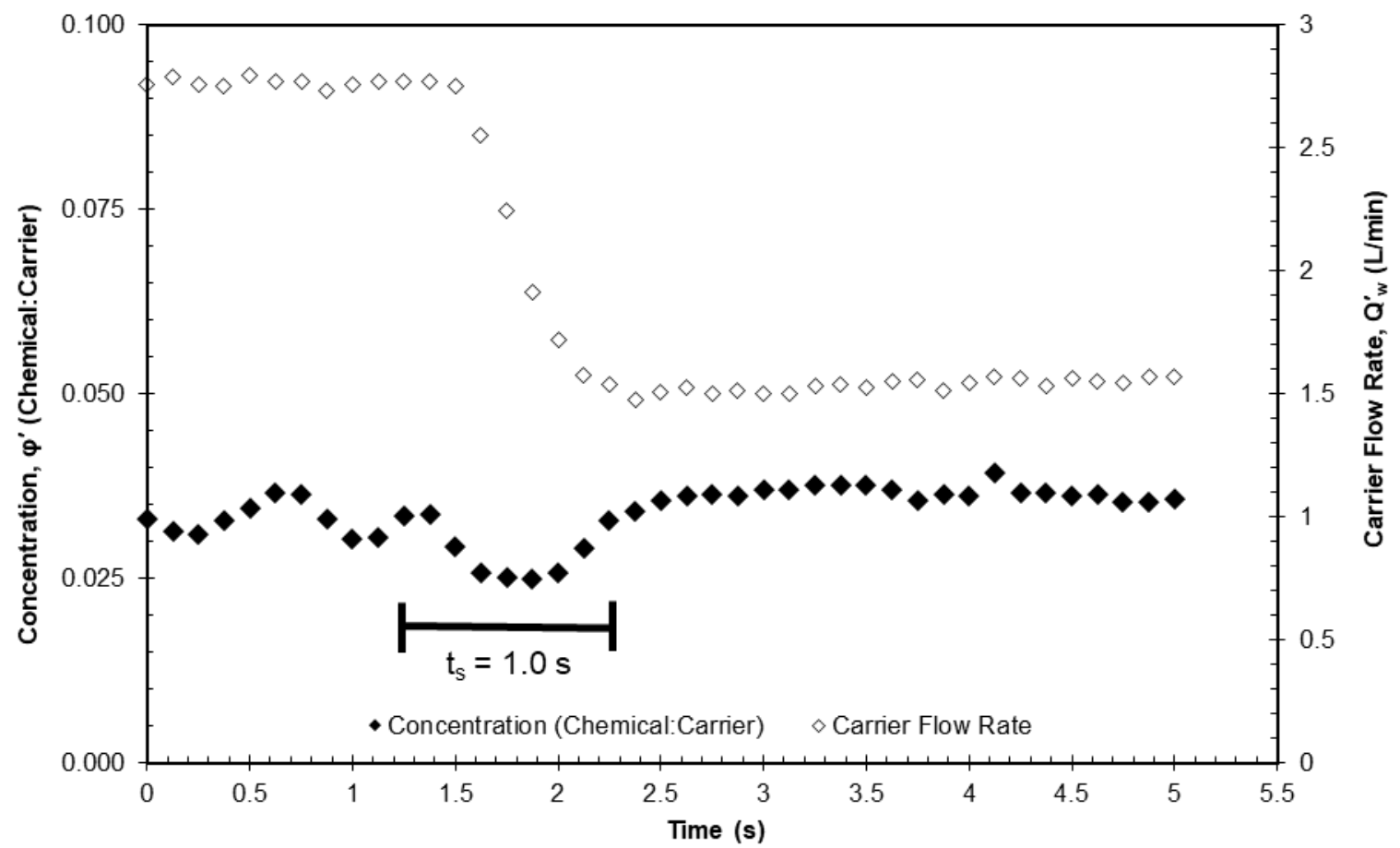

Figure 11: Chemical concentration $\left(\varphi^{\prime}\right)$ and carrier flow rate $\left(Q^{\prime} w\right)$ step-response results for a DCi change of $30 \%$ to $16 \%$ at $1.25 \mathrm{~s}$ (carrier at 0.35 MPa; injector operated at $5.87 \mathrm{MPa}$ and $7 \mathrm{~Hz}$ ).

\section{CONCLUSIONS}

Results of these experiments showed that the open-loop control of the injectors could provide a means of accurately metering the chemical concentrate into the carrier stream. Absorbance measurements of nozzle effluent indicated that the chemical injection rate could be predicted with an average error of 5.4\%. Injection at higher duty cycles resulted in less error in the chemical concentration predictions. Appropriate sizing of the orifice should be considered such that normal operation (for a chosen application rate) would occur at mid-range $\mathrm{DC}_{\mathrm{i}}$ values. Power spectral density tests showed that the injection frequency was noticeable in the nozzle effluent when the injector was operated at 3.04 $\mathrm{MPa}$ and $5 \mathrm{~Hz}$. Increasing the injection pressure and operating frequency to $5.87 \mathrm{MPa}$ and $7 \mathrm{~Hz}$, respectively, improved mixing as the injection frequency component was no longer observed in the effluent samples.

The variable flow nozzle was able to maintain appropriate carrier flow rates to achieve product label chemical concentrations. In one case, the maximum allowable concentrate was exceeded, although the nozzle was able to recover in $0.5 \mathrm{~s}$. Steady state errors ranged from $2.5 \%$ to $7.5 \%$ for chemical concentrations compared to the selected chemical to carrier ratio (0.03614). This test scenario represented an application rate of $4.68 \mathrm{~L} / \mathrm{ha}$ with increases from 4.0 to $7.1 \mathrm{~m} / \mathrm{s}$ and decreases from 7.1 to $4.0 \mathrm{~m} / \mathrm{s}$ which were typical of the field application data example. 
While flow meter and absorbance measurement error may have contributed to chemical metering errors, the injection pressure increase to compensate for carrier pressure in the injection manifold may have also contributed to the errors. This provides justification for accurate flow meter feedback to allow recalibration of the injection system. Thus, a more accurate flow meter for the chemical injection system (unavailable during testing) would likely improve these results.

\section{ACKNOWLEDGEMENTS}

This material is based upon work supported by the Cooperative State Research, Education and Extension Service, U.S. Department of Agriculture, under Agreement No. 2009-0720-1146. Any opinions, findings, conclusions, or recommendations expressed in this publication are those of the author(s) and do not necessarily reflect the views of the U.S. Department of Agriculture.

\section{REFERENCES}

Anglund, E. A., and Ayers, P. D. (2003). Field evaluation of response times for a variable rate (pressure-based and injection) liquid chemical applicator. Appl. Eng. Agric. 19(3): 273-282.

KAWC (Kentucky American Water Company. (2010). Water Quality Report, Kentucky Central Division. Available at: http://www.amwater.com/files/KY_0340250_CCR.pdf. Accessed 5 November, 2011.

Luck, B. D. (2010). Development of a single nozzle, high pressure liquid pesticide metering and injection system. MS thesis. Lexington, Kentucky: University of Kentucky, Department of Biosystems and Agricultural Engineering.

Luck, J. D. (2012). Development of a variable-orifice spray nozzle with high pressure chemical injection for improved pesticide efficacy. Ph.D. Dissertation. Lexington, Kentucky: University of Kentucky, Department of Biosystems and Agricultural Engineering.

Luck, J. D., Sharda, A., Pitla, S. K., Fulton, J. P., \& Shearer, S. A. (2011). A case study concerning the effects of controller response and turning movements on application rate uniformity with a self-propelled sprayer. Trans. ASABE, 54(2), 423-431. http://dx.doi.org/10.13031/2013.36445

Luck, J. D., Shearer, S. A., Luck, B. D., \& Payne, F. A. (2012). Evaluation of a Rhodamine-WT dye/glycerin mixture as a tracer for testing direct injection systems on agricultural sprayers. Appl. Eng. Agric., 28(5), 643-646.

Luck, J. D., Shearer, S. A., Sama, M. P., and Pitla, S. K. (2015). Control system development and response analysis of an electronically actuated variable-orifice nozzle for agricultural pesticide applications. Trans. ASABE, 58(4), 997-1008. 
Luck, J. D., Shearer, S. A., Luck, B. D., and Sama, M. P. (2016). Recalibration methodology to compensate for changing fluid properties in an individual nozzle direct injection system. Trans. ASABE, 59(3), 847-859.

Miller, M. S. and Smith, D. B. (1992). A direct nozzle injection controlled rate spray boom. Trans. ASABE. 35(3): $781-785$.

Qui, W., Watkins, G. A., Sobolik, C. J., and Shearer, S. A. (1998). A feasibility study of direct injection for variablerate herbicide application. Trans. ASABE. 41(2): 291-299.

Steward, B. L. and Humburg, D. S. (2000). Modeling the Raven SCS-700 chemical injection system with carrier control with sprayer simulation. Trans. ASABE. 43(2): 231-245.

Sudduth, K. A., Borgelt, S. C., and Hou, J. (1995). Performance of a chemical injection sprayer system. Appl. Eng. Agric. 11(3): 343-348.

Way, T. R., Von Bargen, K., Grisso, R. D., and Bashford, L. L. (1992). Simulation of chemical application accuracy for injection sprayers. Trans. ASABE. 35(4): 1141-1149.

Zhu, H., Fox, R. D., Ozkan, H. E., Brazee, R. D., and Derksen, R. C. (1998a). A system to determine lag time and mixture uniformity for inline injection sprayers. Appl. Eng. Agric. 14(2): 103-110.

Zhu, H., Fox, R. D., Ozkan, H. E., Brazee, R. D., and Derksen, R. C. (1998b). Mixture uniformity in supply lines and spray patterns of a laboratory injection sprayer. Appl. Eng. Agric. 14(3): 223-230. 